\title{
Artificial Neural Networks to access curve behavior of COVID-19 in Brazil: A learning experience based on other countries
}

\section{Redes Neurais Artificiais para acessar o comportamento da curva de COVID-19 no Brasil: Uma experiência de aprendizagem baseada em outros países}

\author{
Vera Lúcia Milani Martins \\ Instituto Federal de Educação, Ciência e Tecnologia do Rio Grande do Sul, Brasil \\ vera.martins@poa.ifrs.edu.br \\ Fernando Henrique Lermen \\ Universidade Federal do Rio Grande do Sul, Brasil \\ fernando-lermen@hotmail.com \\ Ruane Fernandes de Magalhães \\ Universidade Federal do Rio Grande do Sul, Brasil \\ ruane.magalhaes@gmail.com \\ Gustavo de Souza Matias \\ Universidade Estadual de Maringá, Brasil \\ gusmatias@gmail.com
}

\begin{abstract}
The COVID-19 is considered a pandemic due to global contamination. Brazil lacks precision in estimating the virus's behavior because it has been in the early stages, underestimating notifications of confirmed cases. This study aimed to diagnose the curve behavior of the confirmed cases of COVID-19 in Brazil, based on infected rates, considering the total population and the contaminated population in other countries. For greater accuracy in estimating the Brazilian curve of infected, the Artificial Neural Network structure estimates the population with confirmed cases, combined by the arithmetic mean with SEIR and other estimation methods including ARIMA, SARIMA, trend Holt, and additive Winter. The results showed that, despite maintaining the adopted restriction policies, Brazil tends to face a crisis with a contagion curve below that registered by critical cases such as Spain and the United States, indicating the possibility of the occurrence of 1,000,000 confirmed cases on the $82^{\text {nd }}$ day.
\end{abstract}

Keywords: COVID-19, Infectious diseases, Artificial neural networks, Predictive analytics. 


\section{Resumo}

O COVID-19 é considerado uma pandemia devido à contaminação global. O Brasil carece de precisão na estimativa do comportamento do vírus, pois está nos estágios iniciais, subestimando as notificações de casos confirmados. Este estudo teve como objetivo diagnósticar o comportamento da curva de casos confirmados de COVID-19 no Brasil, com base nas taxas de infecção, considerando a população total e a população de outros países. Para maior precisão na estimativa da curva brasileira de infectados, a estrutura da Rede Neural Artificial estima a população com casos confirmados, combinada pela média aritmética com SEIR e outros métodos incluindo ARIMA, SARIMA, tendência Holt e Winter Aditivo. Os resultados mostraram que, apesar de manter políticas de restrição, o Brasil tende a enfrentar uma crise com uma curva de contágio abaixo da registrada em casos críticos como Espanha e Estados Unidos, indicando possibilidade de ocorrência de 1.000.000 de casos confirmados no $82^{\circ}$ dia.

Palavras-Chave: COVID-19, Doença infecciosa, Rede neural artificial, Análise preditiva.

\section{Introduction.}

Public health issues are relevant factors in the development of the world economy, changing markets, flows of imports and exports, as well as the activities of industry, trade, and tourism (Reeves et al., 2019; Tambo et al., 2019). In epidemics that reach different territories and that cause a high rate of disability among the population, the workforce of different sectors is strongly affected, which reflects the drop in the countries' Gross Domestic Product and their economic standards (PasquiniDescomps et al., 2017). For this reason, the study of the effects of global epidemics requires multidisciplinary analyzes, which can consider the cascading impacts of these events.

Bearing in mind that epidemics can reach large portions of populations, in large territorial spaces, the use of technologies and artificial intelligence provides support to public and health managers in understanding the needs for changes in social dynamics (Shaw et al., 2020). Thus, it is possible to plan the control of public services and economic activities, according to the diseases spread diagnosis and the effects on the affected population. In this sense, even for the essential studies that seek the cure or treatment for these epidemics, the projections analysis has an important role. This fact is due to greater knowledge about how social dynamics are associated with the spread of diseases; the decision-making process for public interventions is now more strongly supported by scenarios with less uncertainty and vulnerability (Joshi et al., 2017; Scarabel et al., 2020). Consequently, from studies of prediction and diagnosis of behaviors over epidemiological weeks, managers can carry out regionalized analyzes and adapted to the characteristics of their social and health systems, such as commerce, local tourism, industry, education, logistics, and hospital infrastructure.

In this scenario, as of December 2019, there was a worldwide need to manage the effects of an epidemic, which directly affected health systems and the global economy, originated from the transformation of Sars-Cov, a virus previously identified in 2003 (Rota et al., 2003). The mutation of this virus, called Sars-Cov-2 or Corona Virus (COVID-19), was predicted by Cheng et al. (2007) and identified in initial cases recorded in China, which reached 82,361 cases in early April 2020. Other studies have presented preliminary estimates of the curve behavior of COVID-19 (Zhuang et al., 2020). Contagion by the virus took on worldwide dimensions, being considered a pandemic on March 11, 2020, by the Word Health Organization (WHO). 
Among the seminal authors of research related to COVID-19 are Huang et al. (2020), with 2870 citations, whose research evaluates the clinical behavior of patients with active cases in Wuhan, China. The work of Guan et al. (2020), with 1701 citations, which sought to characterize the symptoms of patients with COVID-19. Finally, the study Chen et al. (2020), with 1490 citations, developed an epidemiological case study with 99 Chinese patients to assess the behavior of the infectious disease.

Since then, several forecasting studies have been developed, based on the use of different technologies, in order to conduct policies to minimize its effects, such as measures of social isolation and lockdown. One of the strategies used by countries in different epidemics is to estimate the contamination behavior (De Odriozola et al., 2017; Pérez-Castro et al., 2016). These measures aim to provide the least spread of the virus, the displacement of a higher number of health professionals in specialized care, as well as available hospital infrastructure (Benvenuto et al., 2020; Jiang et al., 2020). In this sense, the existence of studies that develop technologies and artificial intelligence assist in the delivery of forecasts, solutions, products, services, and innovations (Wang and Mengjuan Liu; 2019). These solutions can offer a reduction of economic and health population impacts during periods of pandemics. Besides, they provide support for public decision-making, based on mathematical and statistical models, identifying regionalized influencing factors for each affected population. In Brazil, however, most of the models developed to allow the data previously recorded in the country on the number of infected, deaths, and recovered, although there are significant failures related to the testing of suspected cases, as well as a short period of observations (Benvenuto et al., 2020; Lorenz et al., 2020).

Therefore, as a way to support the projections of infected people and thus support the strategies development, applied to public policies, by decision-makers in Brazil, this study aims to develop the diagnosis of the curve behavior of COVID-19 confirmed cases. This diagnosis is based on infected rates, considering the total population and the contaminated population in other countries. To this end, an Artificial Neural Network (ANN) structure was used, based on confirmed cases of COVID19, as of January 22, 2020, in the countries: United States (213,372), Italy (110,574), Spain $(104,118)$, Japan $(2,178)$, and South Korea $(9,887)$, whose data were released by Johns Hopkins University and Medicine. This study not considered the data referring to China, due to its structure of counting cases, observed in days only at the end of January. The selected countries were considered based on the development, and current pandemic stage since Japan and South Korea have already gone through the peak of cases of COVID-19. At the same time, the United States, Spain, Italy, and Brazil are in a situation of the exponential growth of contagion. In this case, ANN can support to analyze problems in different contexts (Martins and Werner, 2012; Zhang et al., 2018), considering epidemiological data in COVID-19 studies (Ghazaly et al., 2020; Mollalo et al., 2020; Saba and Elsheikh, 2020). However, there are still few studies that have used this technique to predict pandemic behavior (Akhatar, Kraemer, and Gardner, 2019; Kawaguchi et al., 2020). In checking the literature, no studies were found that applying this procedure in the prospection of cases of COVID-19.

Therefore this research sought to estimate the cases of infected Brazilians, imported or by community transmission, 14 days ahead, supported by the application of ANN, considering the underreporting effects in the country. The results analysis considered the potential underreporting effects, given that this has been a challenge in facing Covid-19 coping in Brazil, significantly affecting national infection data. Besides, the study and comparison of epidemiological models only, which do not consider such effects, may not adequately represent the contagion behavior in each territory. That is because Brazil has continental dimensions, several states, including, have a territorial 
dimension larger than some European countries. In this way, the region's specificities can influence the contagion factors in the country. The period of 14 days is justified by the average virus incubation time of 5.2 days (95\% confidence interval, 4.1 to 7.0), as identified in 2020 (Jiang et al., 2020; Li et al., 2020) Thus, the model for predicting the behavior of the contaminated curve presents the effects of preventive measures in 14 days. Regarding the proposed forecasting model, this study aims to support the definition of public policies for the development of social dynamics patterns, in order to minimize the effects of COVID-19 contamination on the Brazilian population.

\section{Method.}

The method covered in this study comprises two phases (i) Data organization: Data collection and preparation, detailed in Section 2.1; and (ii) Individual forecasts and combinations: After prediction made via ANN, ARIMA, SARIMA, Holt, Winters additive and, epidemiological model SEIR, the results are combined, forming a single forecast. Sections 2.2 and 2.3 detail these models.

\subsection{Database.}

The data used in this study were those made available by Johns Hopkins University and Medicine on the platform https://coronavirus.jhu.edu/map.html, for being recognized as robust and reliable by the scientific population (Boopathi et al., 2020). The observation of the data included the period between 01/22/2020 and 04/27/2020. Currently, the country has been in confirmed cases of COVID-19 for 62 days. Thus, the organization of the data considered the registration of the first confirmed case as the initial day of contamination in the observed country (day zero).

\subsection{Forecasting.}

The structure of the initial analysis considered the percentage of population referring to new confirmed cases of infection per day, in order to mitigate the effect of absolute cases. The network used for this analysis was MLP (Multilayer Perceptron), with online training and gradient descent as an optimization algorithm. The activating function of the hidden layer is the hyperbolic tangent, and the output function is the identity function. The initial learning rate used was 0.8 , while the training portion used $90 \%$ of the data, both justified by the low number of periods for learning the Brazilian historical series (62 days), other studies use a similar strategy for training (Ahmad and Gromiha, 2002; Zhang, et al., 2018). The records of new cases from the United States, Italy, Spain, Japan, and South Korea were used as covariates in the ANN, thus helping to learn the behavior of the data of newly infected people in Brazil (dependent variable).

The most used way of combining forecasts is usually by obtaining the arithmetic mean of the individual forecasts (Poncela et al., 2011; Taylor and Bunn, 1999); thus, a single and more accurate estimate incorporates characteristics of different curves. The individual forecasting models adopted for the combination were $\operatorname{ARIMA}(\mathrm{p}, \mathrm{d}, \mathrm{q}), \operatorname{SARIMA}(\mathrm{P}, \mathrm{D}, \mathrm{Q})(\mathrm{p}, \mathrm{d}, \mathrm{q})$, adopted in the epidemiological investigation to malaria and dengue about (Duan and Zhang, 2020; Kırbaş et al., 2020; Permanasari et al., 2013), in addition to the Holt trend and Winters additive exponential smoothing models, consolidated in the forecasting literature (Koning et al., 2005; Makridakis and Winkler, 1983). 
For the combination analyzes, the data were considered seasonal, with period seven, since there is an underestimation of the records on weekends. The Eq. 1 described how to obtain the predictions using the ARIMA model. The ARIMA, SARIMA, Holt, and Winters additive models, as well as the ANN, were adjusted using SPSS software.

$$
Z_{t+h}=\varphi Z_{t+h-1}+\cdots+\varphi_{p+d} Z_{t+h-p-d}-\theta_{1} \varepsilon_{t+h-1}-\cdots-\theta_{q} \varepsilon_{t+h-q}+\varepsilon_{t+h}
$$

where: $\varphi_{1}(\beta)=1-\varphi_{1}(\beta)-\varphi_{2}(\beta)^{2}-\cdots-\varphi_{p+d}(\beta)^{p+d}, \beta^{n} Z_{t}=Z_{t-n}$

\subsection{Epidemiological model.}

The SEIR epidemiological model represents the discrete behavior of Susceptible, Exposed, Infected, and Recovered. The Susceptible population (S) treats the population of the region where the virus circulates, the Exposed population (E) treats people who contracted the virus in the period but are still in the latency phase, the Infected population (I) treats people who present the virus symptomatically, and the Recovered $(\mathrm{R})$ population treats people who have recovered from the infection. The population's behavior influences this model, whose dynamics interfere with the infection process. The SEIR model constants refer to person-to-person contamination rates, the time and incubation of the virus, and the infection duration (Han and Lei, 2019; Lu and Lu, 2018; Zhao et al., 2018).

As the population variation, due to deaths, emigration, migration, and births, is usually low during the period when an epidemic is studied, it is possible to consider the total population constant for the use of the SEIR model. Several studies assume this premise (Zhao et al., 2018), including the case of the present study.

The individual prediction models, as well as the initial estimate made by the ANN, were combined with the curve described by the epidemiological model SEIR, consolidated in the literature to assess the spread of infections. The SEIR model represented by population susceptibles, exposed, infected, and recovered can be described by Eq. 2, 3, 4, and 5. For the model resolution, the values of $1 / 10^{-1}$ day and $(1 / 5.2)^{-1}$ day were adopted for the recovery period $(\gamma)$ and latent period $(\delta)$, respectively, as indicated by the WHO (2020). The $\beta$ infection rate was adjusted to experimental values by the $n l s$ function of the R-Project. For the numerical integration of the model, the rk4 function of the deSolve package was used, based on the fourth-order Runge-Kutta method. The input parameters adopted were those corresponding to the values of S, E, I, and R, on the first day of the beginning of the epidemic in Brazil. The adjusted $\beta$ value was $2.616 \times 10^{-09}$.

$$
\begin{aligned}
& \frac{d S}{d t}=-\beta I(t) S(t) \\
& \frac{d E}{d t}=\beta I(t) S(t)-\delta E(t) \\
& \frac{d I}{d t}=\delta E(t)-\gamma I(t) \\
& \frac{d R}{d t}=\gamma I(t)
\end{aligned}
$$

where: $\mathrm{S}$ is the number of the Susceptibles, $\mathrm{E}$ is Exposed, I is Infected, and $\mathrm{R}$ is Recovered; $\beta$ is the transmission rate from $\mathrm{S}$ to $\mathrm{E} ; \delta$ is the transmission rate from $\mathrm{E}$ to $\mathrm{I}, \mathrm{e} ; \gamma$ is the transmission rate from E to R. 


\section{Results.}

When looking only at the number of contaminated, one can have the wrong impression about the contamination rate of each country, as they have different territorial extensions and population. In this context, although the absolute number of contaminated is not the worst observed, Spain recorded the worst scenario, to the population percentage with confirmed cases of the COVID-19 among the countries observed. That country presented 9,630 new cases of contamination on its $54^{\text {th }}$ day of registration, which corresponds to approximately $0.02053 \%$ of its total population. In this sense, Brazil, registered its worst moment on the $60^{\text {th }}$ day with 5,281 new cases of COVID-19, corresponding to approximately $0.0025 \%$ of its total population. Fig. 1 presents the comparative results between countries, by infected population (a) and contaminated percentage (b) vs. infection days. These data are confirmed by the Yuan et al. (2020) study, which reports concern about the cases of COVID-19 in Spain due to the high speed of contagion when compared to other European countries.

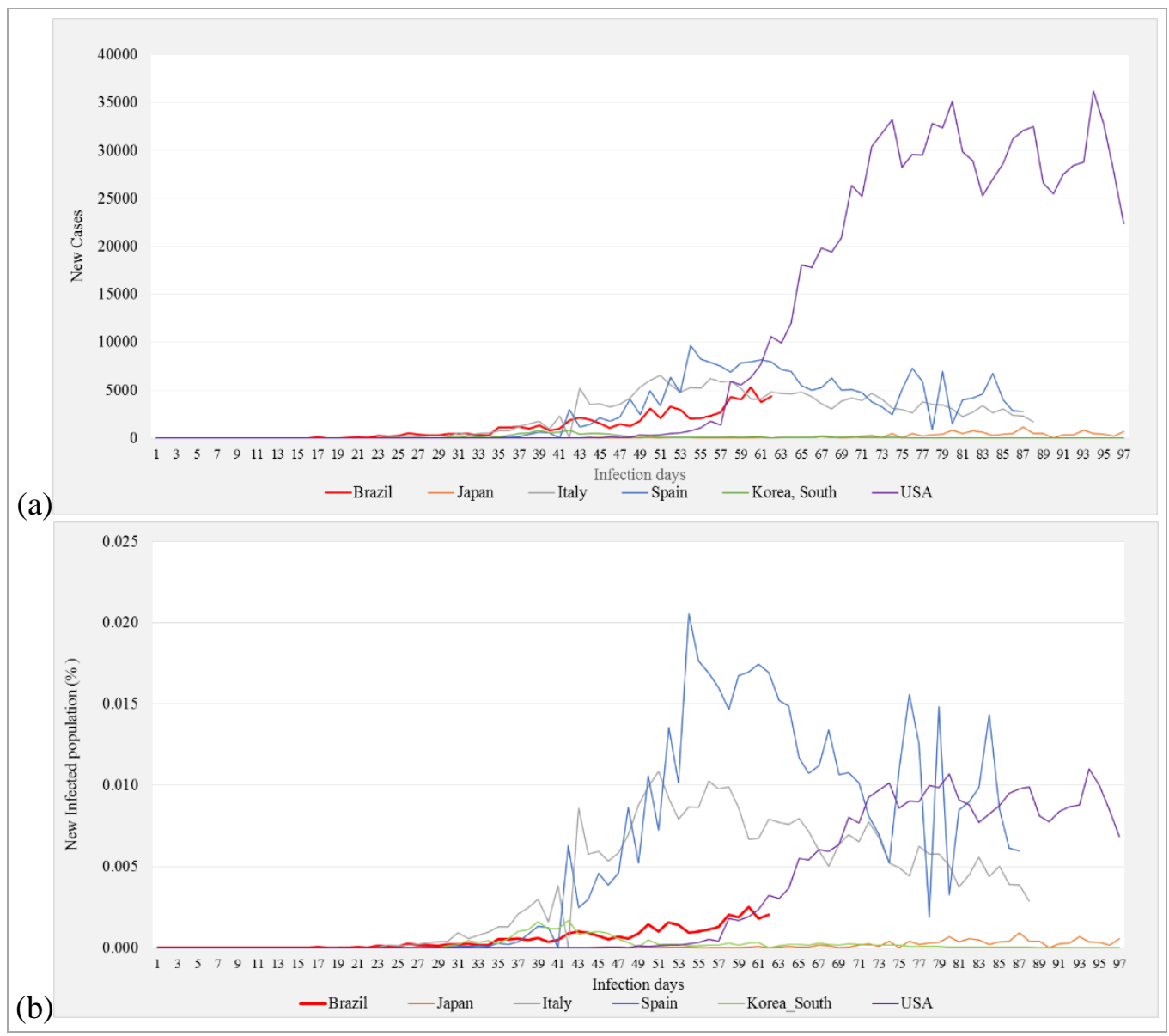

Figure 1: Newly infected population (a) and contaminated percentage (b) vs. infection days

The percentage characteristics of the population with confirmed cases in other countries may contribute to the estimation of the percentage curve of the population with confirmed cases in Brazil. In this way, the historical information observed in countries affected by the epidemic can be 
incorporated to train an ANN for new daily cases in Brazil. Since the governmental measures adopted are different, with different rates of population adherence between countries, the development of a curve without considering different scenarios may incur inadequate strategic measures to combat the pandemic. The relationship between government and science during pandemic periods is defended by Chow et al., (2020), who reports that these actors must work diligently to understand and act accordingly, in order to minimize the adverse effects on populations.

The ANN trained in this study developed its learning from the pandemic behavior data of each country considered, until the $97^{\text {th }}$ day. Thus, predicted results showed for new daily cases in Brazil, in terms of the percentage of its population. The final analysis used $87.1 \%$ of the total data for training and $12.9 \%$ for testing. The hidden layer composed of 5 units, in addition to the bias. The relative error of the learning was 0.058 , while the relative error of the test partition was 0.043. Fig.2 shown the resulting synaptic weight structure. The contribution (weight) of the covariates in the ANN model was in the order of USA 0.499, Italy 0.206, Japan 0.143, Korea South 0.115, and Spain 0.037.

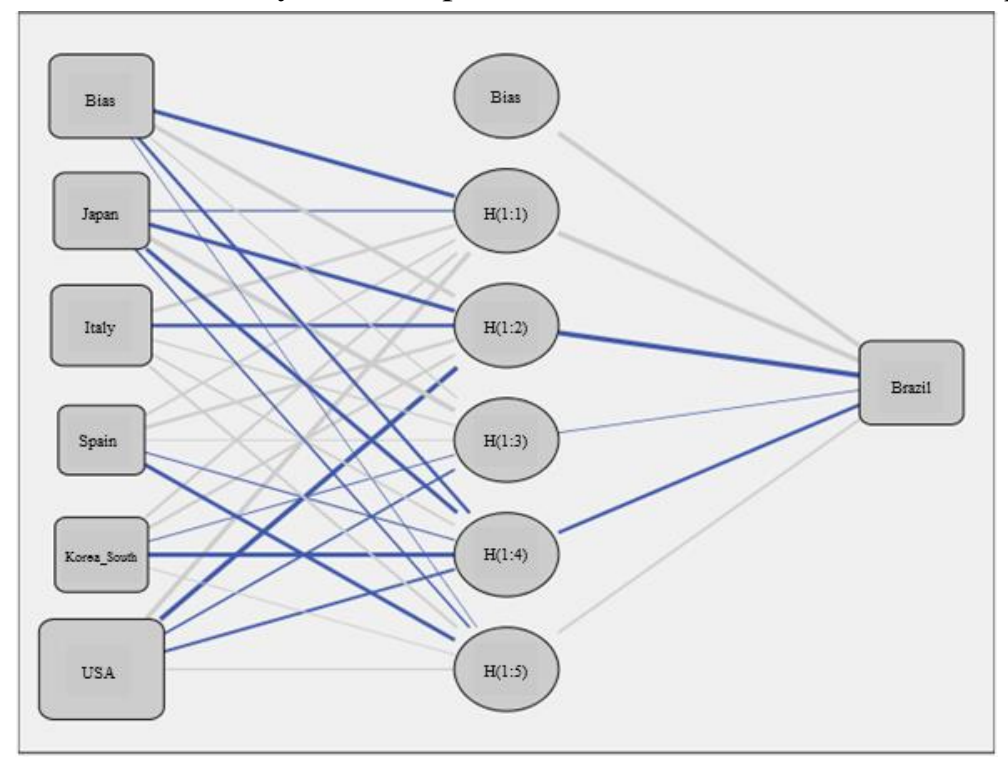

Figure 2: ANN architecture with inputs, hidden layers, and outputs

Note: Grey - Synaptic weighting > 0; Blue - Synaptic weighting $<0$

With the learned behavior, it was possible to observe that the public policies adopted until the study's analysis data were able to keep the rate of new cases below $0.002 \%$ of the total population for the next 14 days, as shown in Fig. 3. The influence of measures to intervene in social dynamics in COVID-19 case reduction actions, published by Haines et al. (2020), presents decisions made by the United Kingdom government that influence the contingency of viruses in the country. 


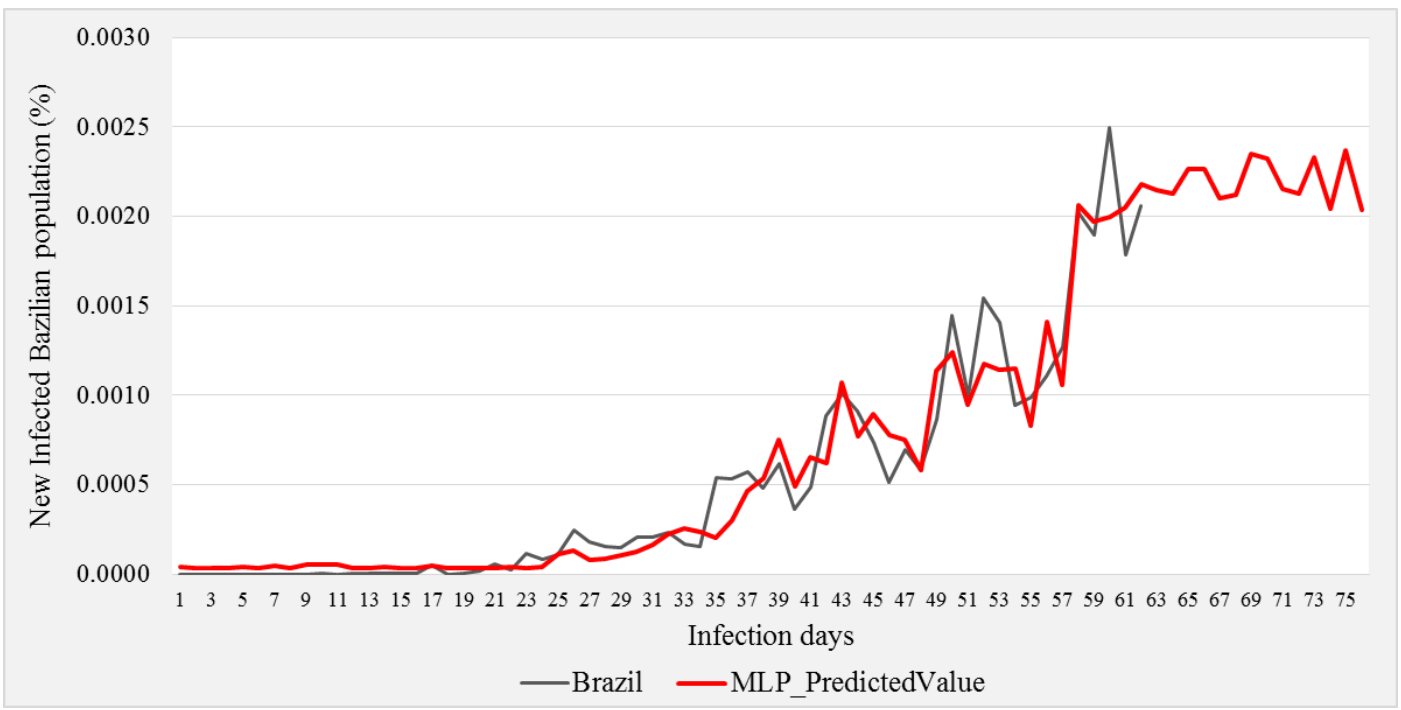

Figure 3: Situation Brazil and estimated curve by MLP

The analyzes carried out in this study sought to estimate new cases in Brazil for 14 days, which corresponds to the isolation time recommended by WHO, (2020) in order to avoid contagion. The results obtained varied between 4,308 and 5,007 cases. This interval, considered positive when compared to cases registered in European countries (Haines et al., 2020). Tab. 1. presents these results.

Table 1: Estimated population with COVID-19 confirmed for 14 days in Brazil

\begin{tabular}{ccc}
\hline Infection days & \% Estimated & Estimated pop \\
\hline 63 & 0.00215 & 4,539 \\
64 & 0.00213 & 4,494 \\
65 & 0.00227 & 4,792 \\
66 & 0.00226 & 4,784 \\
67 & 0.00210 & 4,438 \\
68 & 0.00212 & 4,487 \\
69 & 0.00235 & 4,972 \\
70 & 0.00232 & 4,908 \\
71 & 0.00216 & 4,555 \\
72 & 0.00212 & 4,491 \\
73 & 0.00233 & 4,921 \\
74 & 0.00204 & 4,318 \\
75 & 0.00237 & 5,007 \\
76 & 0.00204 & 4,308 \\
\hline
\end{tabular}

The results of case estimates were combined using the arithmetic mean, considered one of the most consolidated forms for combining forecasts (Martins and Werner, 2012; Taylor and Bunn, 1999) and assumes that individual forecasts influence the final forecast in equal proportion. The 
combination of forecasts is a resource recognized in the literature for improving the quality of individual forecasts (Martins and Werner, 2012). In this sense, some authors argue that simpler ways of combining predictions, such as those made in this study, can produce equally satisfactory results when compared to more complex models (Koning et al., 2005; Makridakis and Winkler, 1983).

The individual models ARIMA, SARIMA, linear trend of Holt, additive model of Winters and SEIR (infected), and ANN produced forecasts for the next 35 days, coinciding with the $97^{\text {th }}$ day of confirmed cases in Brazil. The quality of the adjustment, represented by the difference between the estimated values and the observed values (Fig.4).

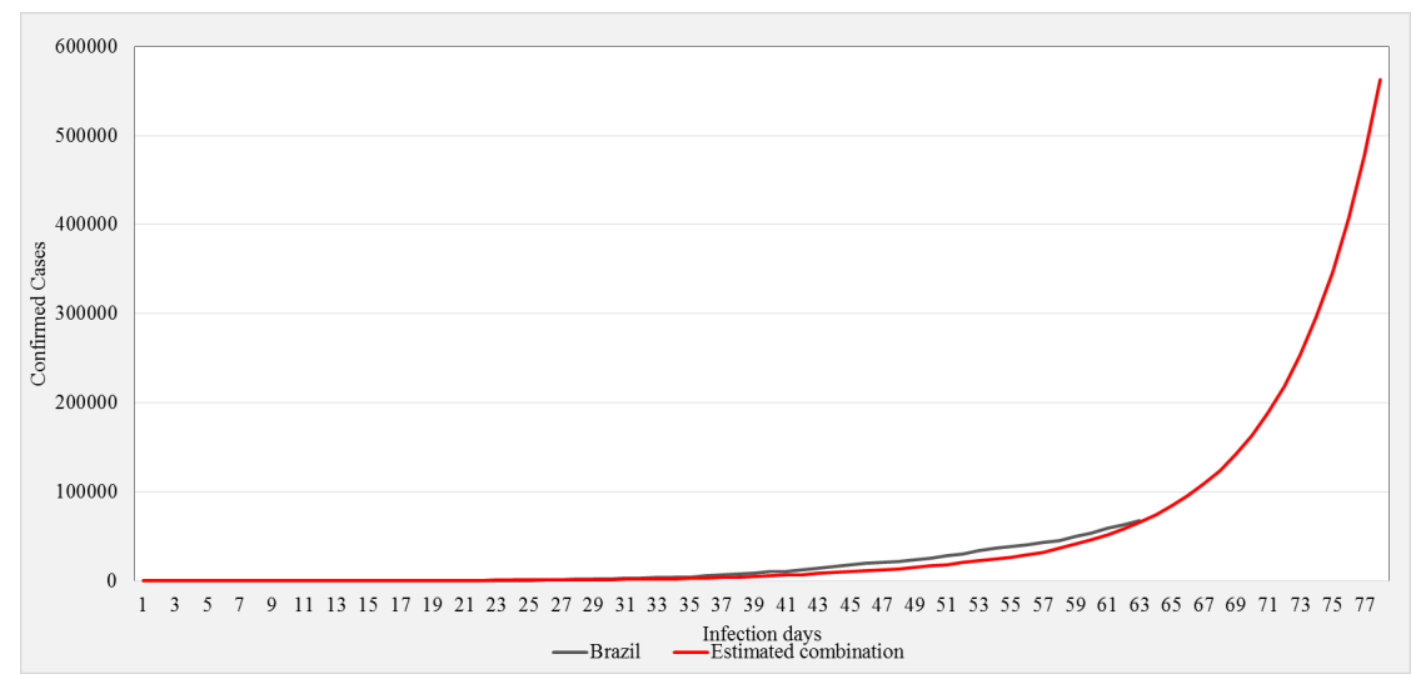

Figure 4: Brazil Situation and Estimated Curve by Combination

Fig. 4 shows the observed and predicted data up to the $67^{\text {th }}$ day of confirmed cases, at which point estimates that the 100,000 infected mark would be exceeded. Between the $68^{\text {th }}$ day and the $78^{\text {th }}$ day, a more marked increase in cases can be observed, from 124,000 cases to 563,054 confirmed cases. This change in the behavior of the curve makes it difficult to visualize the comparison between the confirmed cases observed and those estimated in the same graphical representation. Based on the increase in the expectation of contagion captured by the estimate, the other values listed (Fig. 5). Several authors reported facing the same challenge in estimating the behavior of COVID-19, as Benvenuto et al., (2020) in their studies. 


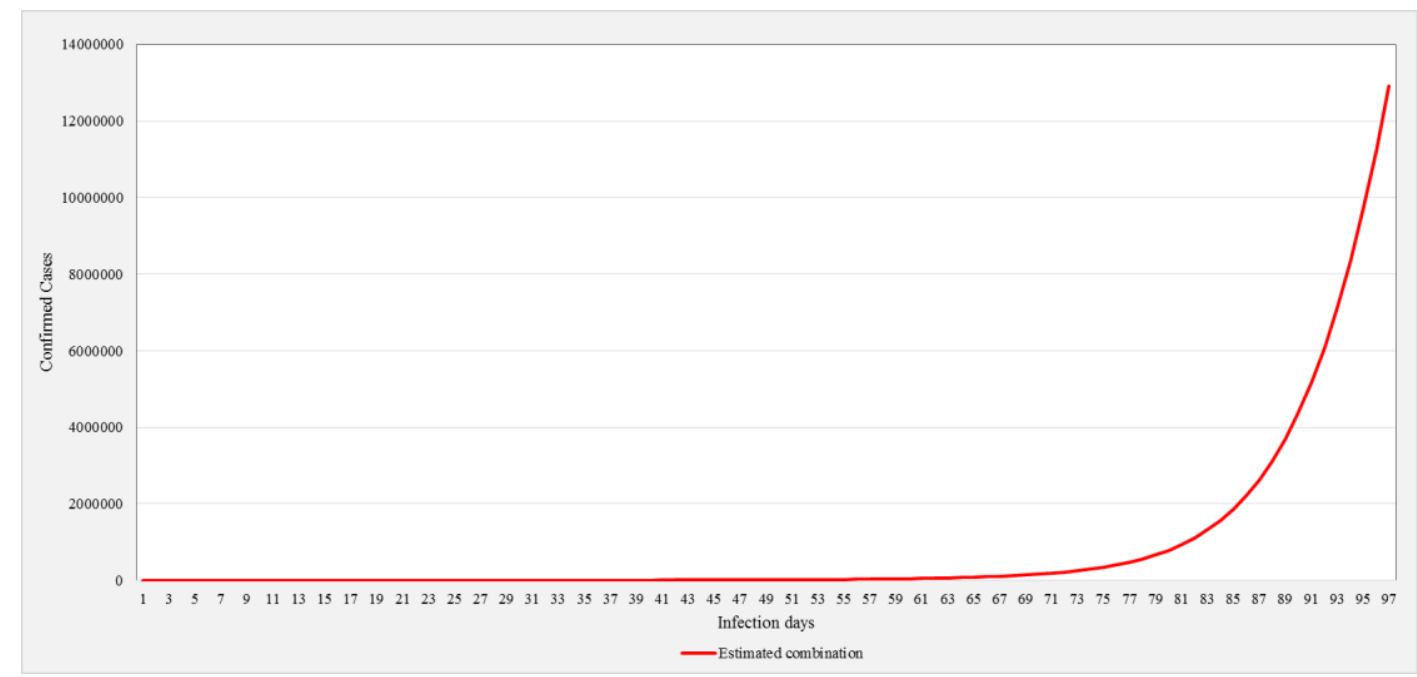

Figure 5: Estimated Curve by Combination

In Fig. 5, the combined case forecast is estimated up to the $97^{\text {th }}$ day, in which more than $12,904,819$ cumulative confirmed cases are forecast. In this curve, the mark of 100,000 cases is exceeded on the $67^{\text {th }}$ day $(108,695$ estimated cases $)$, is estimated, on the $82^{\text {nd }}$ day, more than $1,000,000$ cases $\left(1,107,417\right.$ cases). In the interval of nine days, on the $91^{\text {st }}$ day, the record of 5,000,000 cases $(5,157,696$ estimated cases) can be exceeded. The forecast combination estimates that, at the beginning of the contamination peak, on the $97^{\text {th }}$ day, $6.11 \%$ of the Brazilian population will be infected. To the SEIR model, this number is $12.1 \%$; however, this epidemiological model does not consider the adoption of new public policies of social restriction, such as horizontal isolation, quarantine, or lockdown, which can decisively affect these estimates. These results, when compared with real data, indicated that Brazil reached the milestone of 1,000,000 cases on the 115th epidemiological day, resulting in a difference of 19 days concerning that predicted by the model. Such difference may be due to the circulation restriction policies adopted, the error of the model inherent in the forecasting processes, and the underreporting evidenced recently by EPICOVID19; a sample study carried out in 90 Brazilian cities that infers that the notified cases can be seven times smaller than the ones real (UFPeL, 2020).

\section{Discussions.}

The number of the infected population in Brazil indicates that in Latin America, it may be the country with the highest number of contamination, in accord with the study presented by RodriguezMorales et al. (2020). On the other hand, it may also present contagion on a smaller scale, when compared to European countries.

Regarding the relatively smaller scale contagion, analyzing in Fig. 3, it is relevant to note that Brazil does not yet use the mass testing strategy, which can trigger the underreporting of new officially registered cases. However, the low level of testing could also be observed in China, during the first weeks of the COVID-19 epidemic. In their study, Gong et al. (2020) concluded that the adequacy and authenticity of available information could influence the behavior of populations in epidemics. This fact occurs because the contagion data adequately communicated can result in higher rates of adherence to the control measures adopted. As a result, in the medium and long term, 
economic losses resulting from such limitations are reduced. Thus, with notifications of confirmed cases become more reliable, managers can guide policies to release or restrict the functioning of services and mobility standards, in order to expand the defense and prevention of populations to the risks of contagion, in a structured way. In this sense, the results that assess the infection speed in Brazil reflects the underreporting effects strongly. These results are not compatible with the predictions and the behavior of the disease in the population. Consequently, in addition to the fact that the country's official data is affected, impacting on studies of infection prediction, decisionmaking for the implementation of public policies, in this case, can be based on a distorted perspective.

Therefore, although several policies for releasing and controlling activities have considered, in the Brazilian states, data on the occupancy of ICU beds, such information, in several cases, is compared to the local contagion speed. The contagion information analysis then results from specific isolation levels for each scenario. For this reason, case underreporting and mass testing efforts can be determinants in the proper conduct of pandemic control strategies, as seen in countries such as Germany and New Zealand.

The estimated observed in this study present variability sharp in the final of the ascendant curve. The main factor influencing the variation in these forecasts is associated with uncertainty in confirmed cases, resulting from failures in testing, especially in undeveloped and developing countries. In contrast to the low rate of tests, in some cases, it is also possible to observe that those contaminated with COVID-19 usually seek medical help in the first days when they present symptoms (Sallard et al., 2020). These symptoms can be mild and, as a consequence, would not require hospital care. However, this behavior can induce a collapse in the country's health system, although without a definite increase in the estimated curve of confirmed cases of COVID-19.

From the analysis of the estimates of COVID-19 confirmed cases, as well the curve behavior of the until the $97^{\text {th }}$ day of infection, there is an indication that Brazil may face the epidemiological crisis with a curve of the percentage of infected population below critical cases, like Spain and the United States of America. In Spain, however, only a significant reduction in cases was noticed after the 104th epidemiological day, which was related to the restriction measures implemented in the country. Its first day without a death toll occurred on June 1, the 120th day of the pandemic in Spanish territory. Until the $48^{\text {th }}$ day, the percentage curve of contaminated in Brazil was similar to South Korea and Japan. This estimate considers the maintenance of the restriction policies currently adopted in the country, which have different levels, depending on the affected region. In some places, social isolation measures adopted from the first epidemiological weeks, which contributed to the control of the number of confirmed cases. However, isolation relaxation decisions in implementation can already be noticed, precisely based on the number of registered cases and the apparent change in the curve.

As previously discussed, changes in policy guidelines on restriction policies can cause insecurity in populations, due to the short form of communication, leading to low levels of adherence to recommendations, as well as panic behaviors that can disrupt health systems. For these reasons, and considering the high Brazilian population rate, it is understood that there is a need to strengthen public policies to control social dynamics in order to reduce estimates of infected cases. The public policies suggested are extensive testing of COVID-19, promotion of means of dissemination and awareness of the populations regarding the necessary care against contagion, increase of health professionals and beds available in intensive care units, construction of field hospitals. Besides control of the activities of commerce, industry, tourism, education and circulation, and the provision of financial assistance so that the population can stay away from non-essential work activities. 
Forecasting studies, as developed in the present study, can assist decision-makers and public managers in guiding the isolation measures in a regionalized way. Therefore, according to the mitigation responses to contagion, it is possible to manage different strategies, which can maintain the basic functioning of health systems, serving the affected population.

\section{Conclusions.}

This study developed a diagnosis of the curve behavior of COVID-19 confirmed cases in Brazil, based on infected rates, considering the total population and the contaminated population in other countries. The percentage of population estimates for Brazilian confirmed cases was obtained by ANN, using information from other countries for learning. The curve estimate using an ANN structure, combined by mean with ARIMA, SARIMA, Holt, Winters additive estimates, and SEIR (epidemiological) models.

The number of days with confirmed cases in Brazil is a limitation of the research, mainly due to the uncertainty caused by the lack of mass testing of the population. However, in order to overcome this problem, the use of ANN with the incorporation of the curve behavior of countries that have cases registered in a more extended period was positive, generating relevant analytical results.

From these results, it was possible to observe that the estimate of confirmed cases generated by the combination of six different forecasts indicates that Brazil tends to face the epidemiological crisis in a similar way to the United States of America. For the pandemic control in the country, it is recommended to continue the adoption of public policies of social restriction and overcome the obstacles related to underreporting. Finally, for future research, we suggest the development of this study with data from a more extended period of COVID-19 contagion, to verify the effects of the isolation measures adopted.

Conflicts of Interest: The authors declare that they have no conflicts of interest to report regarding the present study.

Acknowledgments: The author(s) received funding for this study by CAPES Foundation and Federal Institute of Science, Technology, and Education of Rio Grande do Sul.

\section{References}

AHMAD, S.; GROMIHA, M. M. NETASA: Neural network based prediction of solvent accessibility. Bioinformatics, 2002.

AKHATAR, M., KRAEMER, M.U.G., GARDNER, L. M. A dynamic neural network model for predicting risk of Zika in real time. BMC Medicine. BMC Medicine, v. 17, n. 1, p. 171, 2019.

BENVENUTO, D.; GIOVANETTI, M.; VASSALlO, L.; ANGELETTI, S.; CICCOZZI, M. Application of the ARIMA model on the COVID-2019 epidemic dataset. Data in Brief, v. 29, p. 105340, 2020. Disponível em: 〈https://linkinghub.elsevier.com/retrieve/pii/S2352340920302341〉. . 
BOOPATHI, S.; POMA, A. B.; KOLANDAIVEL, P. Novel 2019 Coronavirus Structure, Mechanism of Action, Antiviral drug promises and rule out against its treatment. Journal of biomolecular structure \& dynamics, 2020.

CHEN, N.; ZHOU, M.; DONG, X.; et al. Epidemiological and clinical characteristics of 99 cases of 2019 novel coronavirus pneumonia in Wuhan, China: a descriptive study. The Lancet, 2020.

CHENG, V. C. C.; LAU, S. K. P.; WOO, P. C. Y.; YUEN, K. Y. Severe Acute Respiratory Syndrome Coronavirus as an Agent of Emerging and Reemerging Infection. Clinical Microbiology Reviews, v. 20, n. 4, p. 660-694, 2007. Disponível em: <https://cmr.asm.org/content/20/4/660>. .

CHOW, R. A citizen's thoughts about COVID-19. The Lancet, v. 395, n. 10231, p. e65, 2020. Disponível em: <https://linkinghub.elsevier.com/retrieve/pii/S0140673620306929>. .

DUAN, X.; ZHANG, X. ARIMA modelling and forecasting of irregularly patterned COVID-19 outbreaks using Japanese and South Korean data. Data in Brief, 2020.

GHAZALY, N. M.; ABDEL-FATTAH, M. A.; ABD EL-AZIZ, A. A. Novel coronavirus forecasting model using nonlinear autoregressive artificial neural network. International Journal of Advanced Science and Technology, 2020.

GONG, B.; ZHANG, S.; YUAN, L.; CHEN, K. Z. A balance act: minimizing economic loss while controlling novel coronavirus pneumonia. Journal of Chinese Governance, p. 1-20, 2020. Disponível em: <https://www.tandfonline.com/doi/full/10.1080/23812346.2020.1741940>. .

GUAN, W.; NI, Z.; HU, Y.; et al. Clinical characteristics of coronavirus disease 2019 in China. New England Journal of Medicine, 2020.

HAINES, A.; DE BARROS, E. F.; BERLIN, A.; HEYMANN, D. L.; HARRIS, M. J. National UK programme of community health workers for COVID-19 response. The Lancet, v. 395, n. 10231, p. 1173-1175, 2020. Disponível em: <https://linkinghub.elsevier.com/retrieve/pii/S0140673620307352>. .

HAN, S.; LEI, C. Global stability of equilibria of a diffusive SEIR epidemic model with nonlinear incidence. Applied Mathematics Letters, 2019.

HUANG, C.; WANG, Y.; LI, X.; et al. Clinical features of patients infected with 2019 novel coronavirus in Wuhan, China. The Lancet, 2020.

JIANG, X.; RAYNER, S.; LUO, M. Does SARS-CoV-2 has a longer incubation period than SARS and MERS? Journal of Medical Virology, v. 92, n. 5, p. 476-478, 2020. Disponível em: $<$ https://onlinelibrary.wiley.com/doi/abs/10.1002/jmv.25708>. . 
JOSHI, R.; JOHN, O.; JHA, V. The Potential Impact of Public Health Interventions in Preventing Kidney Disease. Seminars in Nephrology, v. 37, n. 3, p. 234-244, 2017. Disponível em: <https://linkinghub.elsevier.com/retrieve/pii/S0270929517300049>. .

KAWAGUCHI, M.; NUKAGA, T.; SEKINE, S.; et al. Mechanism-based integrated assay systems for the prediction of drug-induced liver injury. Toxicology and Applied Pharmacology, v. 394, p. 114958, 2020. Disponível em: 〈https://linkinghub.elsevier.com/retrieve/pii/S0041008X2030082X>.

KIRBAŞ, İ.; SÖZEN, A.; TUNCER, A. D.; KAZANCIOĞLU, F. Ş. Comperative analysis and forecasting of COVID-19 cases in various European countries with ARIMA, NARNN and LSTM approaches. Chaos, Solitons \& Fractals, 2020.

KONING, A. J.; FRANSES, P. H.; HIBON, M.; STEKLER, H. O. The M3 competition: Statistical tests of the results. International Journal of Forecasting, v. 21, n. 3, p. 397-409, 2005. Disponível em: <https://linkinghub.elsevier.com/retrieve/pii/S0169207004000810>. .

LI, Q.; GUAN, X.; WU, P.; et al. Early Transmission Dynamics in Wuhan, China, of Novel Coronavirus-Infected Pneumonia. New England Journal of Medicine, v. 382, n. 13, p. 1199-1207, 2020. Disponível em: <http://www.nejm.org/doi/10.1056/NEJMoa2001316>. .

LORENZ, C.; AZEVEDO, T. S.; CHIARAVALLOTI-NETO, F. COVID-19 and dengue fever: A dangerous combination for the health system in Brazil. Travel Medicine and Infectious Disease, p. 101659, 2020. Disponível em: <https://linkinghub.elsevier.com/retrieve/pii/S1477893920301277>. .

LU, G.; LU, Z. Global asymptotic stability for the SEIRS models with varying total population size. Mathematical Biosciences, 2018.

MAKRIDAKIS, S.; WINKLER, R. L. AVERAGES OF FORECASTS: SOME EMPIRICAL RESULTS. Management Science, 1983.

MARTINS, V. L. M.; WERNER, L. Forecast combination in industrial series: A comparison between individual forecasts and its combinations with and without correlated errors. Expert Systems with Applications, 2012.

MOLLALO, A.; RIVERA, K. M.; VAHEDI, B. Artificial neural network modeling of novel coronavirus (COVID-19) incidence rates across the continental United States. International Journal of Environmental Research and Public Health, 2020.

DE ODRIOZOLA, E. P.; QUINTANA, A. M.; GONZÁLEZ, V.; et al. Towards leprosy elimination by 2020: Forecasts of epidemiological indicators of leprosy in corrientes, a province of northeastern Argentina that is a pioneer in leprosy elimination. Memorias do Instituto Oswaldo Cruz, 2017. 
PASQUINI-DESCOMPS, H.; BRENDER, N.; MARADAN, D. Value for Money in H1N1 Influenza: A Systematic Review of the Cost-Effectiveness of Pandemic Interventions. Value in Health, 2017.

PÉREZ-CASTRO, R.; CASTELLANOS, J. E.; OLANO, V. A.; et al. Detection of all four dengue serotypes in Aedes aegypti female mosquitoes collected in a rural area in Colombia. Memorias do Instituto Oswaldo Cruz, 2016.

PERMANASARI, A. E.; HIDAYAH, I.; BUSTONI, I. A. SARIMA (Seasonal ARIMA) implementation on time series to forecast the number of Malaria incidence. Proceedings - 2013 International Conference on Information Technology and Electrical Engineering: "Intelligent and Green Technologies for Sustainable Development”, ICITEE 2013. Anais... , 2013.

PONCELA, P.; RODRÍGUEZ, J.; SÁNCHEZ-MANGAS, R.; SENRA, E. Forecast combination through dimension reduction techniques. International Journal of Forecasting, 2011.

REEVES, P.; EDMUNDS, K.; SEARLES, A.; WIGGERS, J. Economic evaluations of public health implementation-interventions: a systematic review and guideline for practice. Public Health, 2019.

RODRIGUEZ-MORALES, A. J.; GALLEGO, V.; ESCALERA-ANTEZANA, J. P.; et al. COVID19 in Latin America: The implications of the first confirmed case in Brazil. Travel Medicine and Infectious Disease, 2020.

ROTA, P. A.; OBERSTE, M. S.; MONROE, S. S.; et al. Characterization of a novel coronavirus associated with severe acute respiratory syndrome. Science, 2003.

SABA, A. I.; ELSHEIKH, A. H. Forecasting the prevalence of COVID-19 outbreak in Egypt using nonlinear autoregressive artificial neural networks. Process Safety and Environmental Protection, 2020 .

SALLARD, E.; LESCURE, F. X.; YAZDANPANAH, Y.; MENTRE, F.; PEIFFER-SMADJA, N. Type 1 interferons as a potential treatment against COVID-19. Antiviral Research, 2020.

SCARABEL, F.; PELLIS, L.; BRAGAZZI, N. L.; WU, J. Canada needs to rapidly escalate public health interventions for its COVID-19 mitigation strategies. Infectious Disease Modelling, 2020.

SHAW, R.; KIM, Y.; HUA, J. Governance, technology and citizen behavior in pandemic: Lessons from COVID-19 in East Asia. Progress in Disaster Science, 2020.

TAMBO, E.; KHAYEKA-WANDABWA, C.; MUCHIRI, G. W.; et al. China's Belt and Road Initiative: Incorporating public health measures toward global economic growth and shared prosperity. Global Health Journal, 2019.

TAYLOR, J. W.; BUNN, D. W. Investigating improvements in the accuracy of prediction intervals 
for combinations of forecasts: A simulation study. International Journal of Forecasting, 1999.

UFPEL, C. DE P. E. DA U. F. DE P. Epicovid19-RS - COVID-19 no Brasil: várias epidemias num só país. 2020.

WANG AND MENGJUAN LIU, G. Dynamic Trust Model Based on Service Recommendation in Big Data. Computers, Materials \& Continua, v. 58, n. 3, p. 845-857, 2019. Disponível em: <http://www.techscience.com/cmc/v58n3/23034>. .

WORLD HEALTH ORGANIZATION. Coronavirus disease 2019 (COVID-19). Situation Report (73). .

YUAN, J.; LI, M.; LV, G.; LU, Z. K. Monitoring Transmissibility and Mortality of COVID-19 in Europe. International Journal of Infectious Diseases, 2020.

ZHANG, R.; ZHAO, L.; LOU, W.; et al. Automatic Segmentation of Acute Ischemic Stroke From DWI Using 3-D Fully Convolutional DenseNets. IEEE Transactions on Medical Imaging, 2018.

ZHANG, Y.; CHEN, H.; YANG, B.; et al. Prediction of phosphate concentrate grade based on artificial neural network modeling. Results in Physics, 2018.

ZHAO, D.; SUN, J.; TAN, Y.; WU, J.; DOU, Y. An extended SEIR model considering homepage effect for the information propagation of online social networks. Physica A: Statistical Mechanics and its Applications, 2018.

ZHUANG, Z.; ZHAO, S.; LIN, Q.; et al. Preliminary estimation of the novel coronavirus disease (COVID-19) cases in Iran: A modelling analysis based on overseas cases and air travel data. International Journal of Infectious Diseases, 2020. 